\title{
Lipid profile in oral submucous fibrosis
}

\author{
Ravi Mehrotra*1, Shruti Pandya1, Ajay Kumar Chaudhary², \\ Himanshu Pratap Singh ${ }^{3}$, Ritesh Kumar Jaiswal ${ }^{3}$, Mangal Singh ${ }^{3}$, SC Gupta ${ }^{3}$ \\ and Mamta Singh ${ }^{1}$
}

\begin{abstract}
Address: ${ }^{1}$ Department of Pathology, M.L.N Medical College, Allahabad, India, ${ }^{2}$ Centre for Biotechnology, University of Allahabad, Allahabad, India and ${ }^{3}$ Department of Otolaryngology, M.L.N Medical College, Allahabad, India

Email: Ravi Mehrotra* -rm8509@gmail.com; Shruti Pandya - Shrutigentech@gmail.com; Ajay Kumar Chaudhary - ajaygenome@gmail.com; Himanshu Pratap Singh - himanshus52@gmail.com; Ritesh Kumar Jaiswal - jaiswal.ritesh.ritesh@gmail.com;

Mangal Singh - mangalsingh@yahoo.co.in; SC Gupta - sgscgupta824@gmail.com; Mamta Singh - mrspath25@gmail.com

* Corresponding author
\end{abstract}

Published: 24 July 2009

Lipids in Health and Disease 2009, 8:29 doi:10.1186/1476-5।IX-8-29

This article is available from: http://www.lipidworld.com/content/8/I/29

(C) 2009 Mehrotra et al; licensee BioMed Central Ltd.

This is an Open Access article distributed under the terms of the Creative Commons Attribution License (http://creativecommons.org/licenses/by/2.0), which permits unrestricted use, distribution, and reproduction in any medium, provided the original work is properly cited.
Received: 19 June 2009

Accepted: 24 July 2009

\begin{abstract}
Background: Changes in lipid profile have long been associated with malignancies as lipids play a key role in maintenance of cell integrity. This study evaluated the alterations in extended lipid profile in untreated patients of oral submucous fibrosis (OSMF) and studied the correlation between lipid levels with tobacco consumption.
\end{abstract}

Materials and methods: In this hospital-based study, 65 clinically diagnosed and histopathologically proven patients of OSMF and 42 age and sex matched controls were studied. In these samples serum lipids including: (i) Total cholesterol, (ii) LDL cholesterol (LDLC), (iii) HDL cholesterol (HDLC) (iv) VLDL cholesterol (VLDLC) (v) triglycerides (vi) Apo-Al (viii) Apo-B and (viii) $\mathrm{LPa}$ were analyzed.

Results: A significant decrease in plasma total cholesterol, HDLC and Apo-AI was observed in patients with OSMF as compared to the controls. Thus an inverse relationship between plasma lipid levels and patients was found in OSMF.

Conclusion: The lower levels of plasma cholesterol and other lipid constituents in patients might be due to their increased utilization. The findings strongly warrant an in-depth study of alterations in plasma lipid profile in patients with oral precancerous conditions.

\section{Background}

Oral submucous fibrosis (OSMF) is a chronic disease of the oral cavity, which is characterized by an epithelial and subepithelial inflammatory reaction followed by fibroelastic changes in the submucosa [1]. This disease occurs most commonly in South East Asia but cases have been reported worldwide in countries like Kenya, China, UK, Saudi Arabia and other parts of the world [2]. In India, the authors earlier reported that oral submucous fibrosis constituted the highest number of patients in premalignant group in a tertiary level hospital based study at Allahabad [3]. Tilakaratne et al. reported that areca nut is the main etiological factor for OSMF [4]. Pandya et al., again from Allahabad, confirmed that dohra/paan masala containing areca nut is a major risk factor of OSMF, especially in the younger age group. They also reported an increase in his- 
topathological grading with severity and duration of addiction habit [5]. Excessive use of areca nut may cause fibrosis due to increased synthesis of collagen and induce the production of free radicals and reactive oxygen species, which are responsible for high rate of oxidation/peroxidation of polyunsaturated fatty acids which affect essential constituents of cell membrane and might be involved in tumorigenesis [6,7].

Lipids are major cell membrane components essential for various biological functions including cell growth and division of normal and malignant tissues. They are homogeneous group of compounds related more by physical than chemical properties. An alteration in the circulatory cholesterol levels has been found to be associated in the etiology of breast cancer and colorectal cancer [8]. However, only a few reports are available on plasma lipid profile in head and neck lesions $[9,10]$.

A careful search of the literature does not reveal any research in extended lipid profiles in OSMF, and to the best of our knowledge this is the first report of its kind.

\section{Materials and methods}

A hospital based study was conducted in 65 clinically diagnosed and histopathologically proven patients of OSMF attending the outpatient department in the division of Otolaryngology of the Swaroop Rani Nehru Hospital, a tertiary level referral hospital affiliated to the Moti Lal Nehru Medical College, Allahabad, India after the institutional ethical committee clearance. All the patients underwent recording of signs, symptoms, detailed history including habits, histopathology and extended lipid profile estimation. 42 healthy individuals, matched for age and sex, who had no complaint or any other major illness in recent past, were included as controls.

Fasting blood samples were collected in plain vials. Serum was collected after centrifugation and stored at $-80^{\circ} \mathrm{C}$ until analyzed. Plasma levels of cholesterol, triglycerides, VLDL, HDL and LDL were calculated by using Autospan Reagents (Span Diagnostics, India). Simultaneously, Apo$\mathrm{A}_{1}$, Apo-B and LPa were estimated by Electrophoresis by the standard technique. Statistical analysis, including calculation of coefficient of variation and Standard deviation was performed utilizing SPSS package. (Tokyo, Japan)

\section{Results}

Sixty five cases of OSMF were studied. Maximum patients (30; 46.2\%) were in their second decade (21-30 yrs) of life with a male predominance. According to the addiction habits, $26(40 \%)$ consumed paan masala or dohra (a locally available combination of slaked lime and areca nut), $30.8 \%$ patients were addicted to betel quid with tobacco while 16 (24.6\%) were smokers. Only 3 (6.6\%) did not have any habit. 12 (18.5\%) patients had a burning sensation in mouth, $16(24.6 \%)$ had ulceration in the oral cavity, $15(23 \%)$ had excessive salivation while 22 $(33.7 \%)$ had difficulty in opening the mouth (trismus) (Figure 1). On clinical grading of trismus, 5 patients were found to have grade I $(>3 \mathrm{~cm}), 34$ had grade II $(2-3 \mathrm{~cm})$, and 26 had grade III $(<2 \mathrm{~cm})$ (Table 1$) .28$ patients consumed paan masala and betel quid with tobacco for 1115 years (1-10 times/day), while 17 patients were addicted for 6-10 years (11-20 times/day) (Table 2).

There was a significant increase in serum total cholesterol, LDL, VLDL and triglycerides levels (Figure 2, 3, 4). On the other hand, there was significant decrease in HDL and Apo-A1 (Figure 5, 6). No change was observed in Apo-B or Lipoprotein-A (Figure 7,8 ) in the patient category compared to the controls (Table 3 ).

\section{Discussion}

Oral submucous fibrosis has always been a challenging disease with high prevalence in India. In this study, most of the OSMF cases were in the second and third decades of life with a male preponderance and addiction to areca nut. This is in accordance with previous reports from the authors as well other groups. As this is a disease of multifactorial etiology, various workers have proposed different theories of causation to establish the exact nature of the disease [11]. Pan Masala/Dohra were the most significant risk factor in this study but no correlation was found with the lipid profile Lipid Research Clinics Coronary Primary Prevention Trial was a multicentere, double blinded, placebo-controlled trial of the bile acid sequestrant, cholestyramine, among type Ha hypercholesterolemic men, i.e., men with elevated total serum cholesterol due to low-density lipoprotein cholesterol. The trial tested the

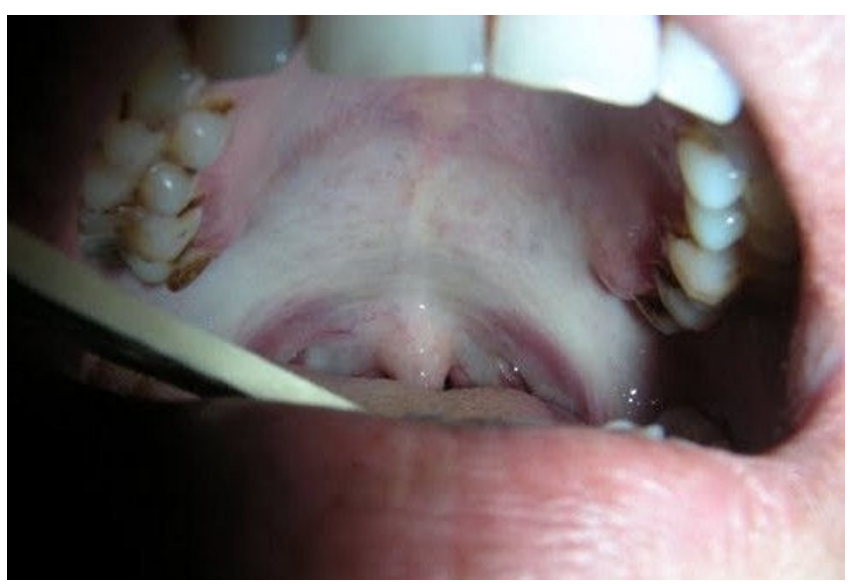

Figure I

Showing clinical picture (blanching and fibrosis) in oral submucous fibrosis. 
Table I: Clinico-pathological attributes in patients of OSMF

\begin{tabular}{llc}
\hline Details & $\mathbf{N}=65$ & (\%) \\
\hline Age (Years) & & $(10.8)$ \\
\hline$\leq 11-20$ & 07 & $(46.2)$ \\
\hline $21-30$ & 30 & $(26.2)$ \\
\hline $31-40$ & 17 & $(6.1)$ \\
\hline $41-50$ & 04 & $(10.8)$ \\
\hline$>51-60$
\end{tabular}

\section{Gender}

Male

\section{Personal habits}

\begin{tabular}{|c|c|c|}
\hline Pan masala or Dohra & 20 & $(30.8)$ \\
\hline Betel quid with tobacco & 16 & $(24.6)$ \\
\hline Smoker (cigarettes/bidis) & 26 & $(40)$ \\
\hline No habit & 03 & $(6.6)$ \\
\hline \multicolumn{3}{|l|}{ Clinical Symptoms } \\
\hline Burning sensation in mouth & 12 & $(18.5)$ \\
\hline Ulceration of oral cavity & 16 & $(24.6)$ \\
\hline Difficulty in mouth opening & 22 & (33.7) \\
\hline Excessive salivation & 15 & $(23.0)$ \\
\hline \multicolumn{3}{|l|}{ Clinical Signs } \\
\hline Grade I $(>3 \mathrm{~cm})$ & 05 & (7.7) \\
\hline Grade II $(2-3 \mathrm{~cm})$ & 34 & $(52.3)$ \\
\hline Gradelll $(<2 \mathrm{~cm})$ & 26 & $(40)$ \\
\hline
\end{tabular}


Table 2: Distribution of tobacco consumption in relation to duration and no. of Pan Masala/Betel quids with tobacco/cigarettes/bidis smoked/day

\begin{tabular}{lllll}
\hline Duration in Year & Mean & \multicolumn{2}{l}{ No. of Pan Masala/Betel quid with tobacco/cigarettes/bidis smoked/day } & Total \\
\cline { 3 - 6 } & & I-10 times/day & 1 I-20 times/day & 10 \\
\hline $1-5$ & 03 & 04 & 06 & 17 \\
\hline $6-10$ & 08 & 08 & 10 & 28 \\
\hline $11-15$ & 13 & 18 & 04 & 10 \\
\hline $16-20$ & 18 & 06 & 09
\end{tabular}

hypothesis that long-term reduction of serum cholesterol leads to a lowered incidence of coronary heart disease. The results indicate that there is a decrease in plasma cholesterol levels associated with cancer apparent within 20 months of diagnosis in patients diagnosed with nonlocalized disease. Of the lipoprotein fractions, LDL-C most clearly reflects the decrease in total cholesterol.

The role of HDL-C and triglycerides in explaining the overall pattern of total cholesterol change is less clear [12].

Cholesterol is an amphipathic lipid and as such is an essential structural component of all cell membranes and of the outer layer of plasma lipoproteins. It is present in tissues and in plasma lipoprotein either as free cholesterol or combined with a long-chain fatty acid, as cholesteryl ester. It is synthesized in many tissues from acetyl-CoA and is ultimately eliminated from the body in the bile as

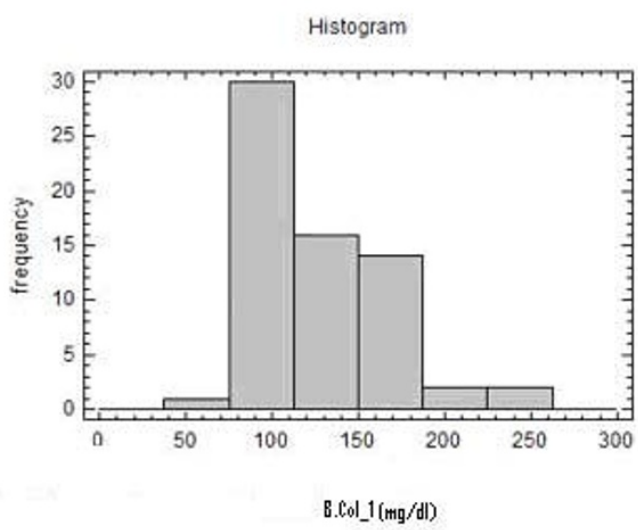

Bar diagram 1: showing value of total Cholesternl in patients of OSMF

Figure 2

Showing Value of Total Cholesterol in patients of OSMF. cholesterol or bile salts [13]. Lipoprotein transports free cholesterol in the circulation, where it readily equilibrates cholesterol in other lipoproteins and in membranes.

Cholesteryl ester is a stored form of cholesterol found in most tissues. It is transported as cargo in the hydrophobic core of lipoproteins [14]. So, the fact that cholesterol in a hydrophobic molecule, which resides in lipoproteins and cell membranes, raises two questions: (i) how does the cell sense the level of cholesterol? (ii) how in this cholesterol specific signaling transmitted to the nucleus for the regulation of various genes? Recent studies directed to resolve these questions, led to the discovery of a novel cell surface cholesterol-sensor designated as receptor-Ck which was not only shown to be ubiquitously present in various human organs but also [through its signaling pathway] regulated various genes involved in cholesterol homeostasis [HMG CoA synthase; HMG CoA reductase; Apo-B-specific LDL - receptor]; cell growth [cyclin D; C -

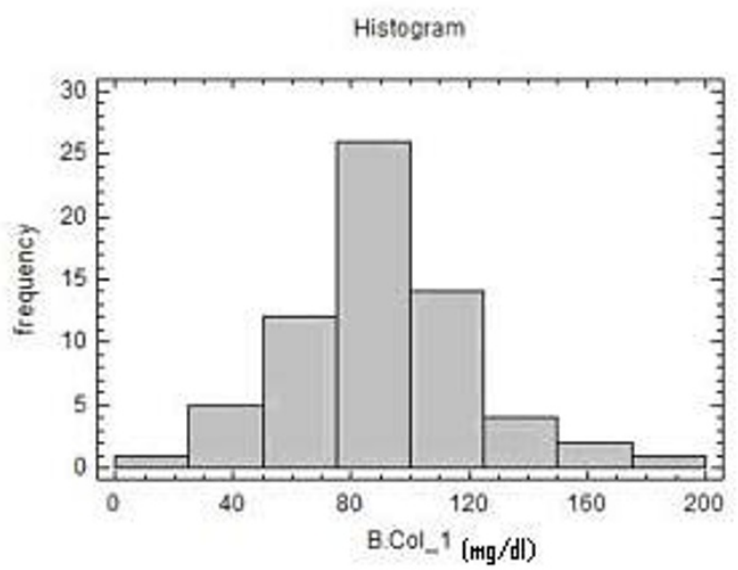

Bar Chart 2: Showing value of LDL in patents of OSMF

Figure 3

Showing Value of LDL in patients of OSMF. 


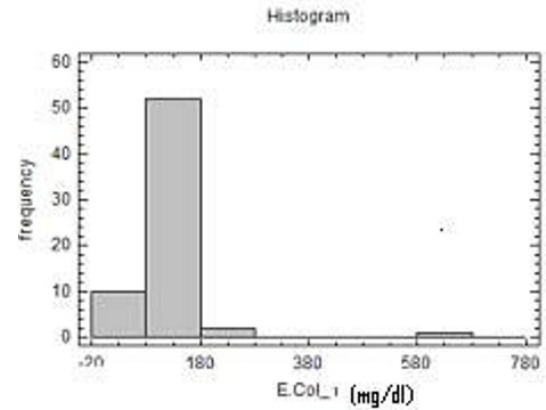

Bar Chart 3: Showing value of S.triglyceride in patients of OSWF

Figure 4

Showing Value of S. triglyceride in patients of OSMF.

fos; C-myc; p27, etc.]; cell death [Bc1-2] through a $47 \mathrm{kDa}$ transcription factor [derived from the cleavage of $125 \mathrm{kDa}$ SREBP] having affinity for genomic sterol regulatory element [SRE] sequence as well as through other transcription factors [15-19].

Cholesterol is often found distributed non-randomly in domains in membranes [20]. Recent observations suggest that cholesterol exerts many of its actions by maintaining a specialized type of membrane domain, termed "lipid rafts" in a functional state. Lipid rafts are enriched in cholesterol and sphingolipids, and have been thought to act as platform through which signal transduction events are coordinated and pathogens gain entry to infect host cells [21].

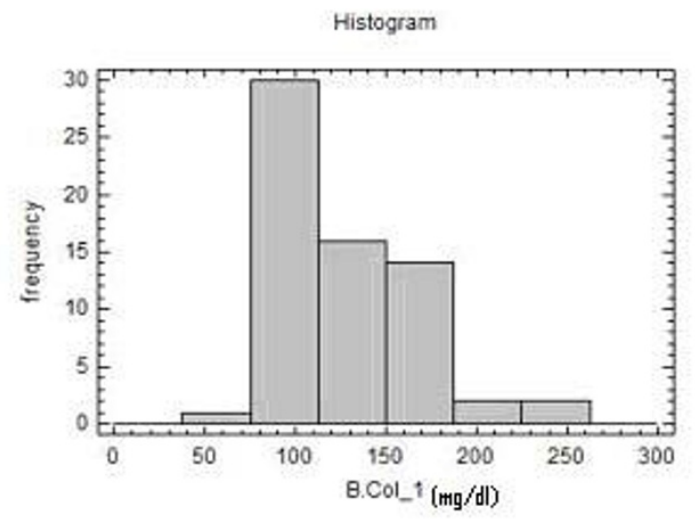

Bar Chart 4: Showing value of $\mathrm{HDL}$ in patients of OSMF

Figure 5

Showing Value of HDL in patients of OSMF.

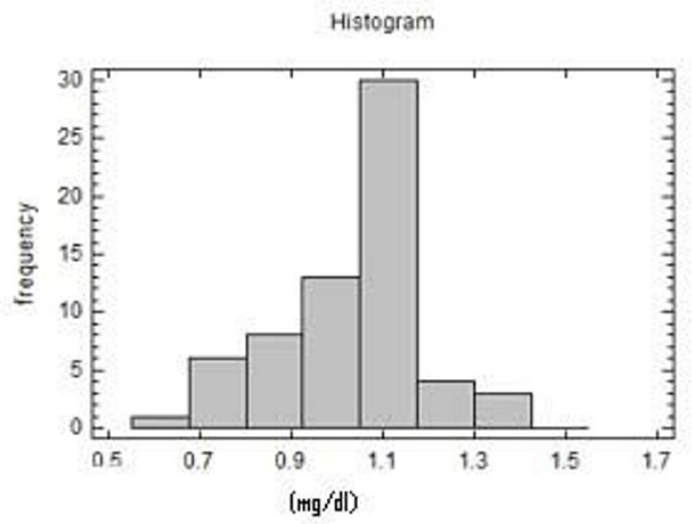

Bar Chart 5: Showing value of Apo-Al in patients of OSHF

Figure 6

Showing Value of Apo-Al in patients of OSMF.

In some malignancies, serum cholesterol undergoes early and significant changes. Low levels of cholesterol in the proliferating tissues and in blood compartments could be due to the rapidly dividing cells in malignancies. Several prospective and retrospective studies have shown an inverse association between blood lipid profiles and different cancers. [22]. Some scientists have observed an inverse trend between lower serum cholesterol and head and neck cancer as well as esophageal and colon cancers [9]. Similar findings were reported by Patel et al 2004 [10].

Earlier studies have shown alteration of plasma lipid profiles in head and neck and other cancers [10]. Lipids are

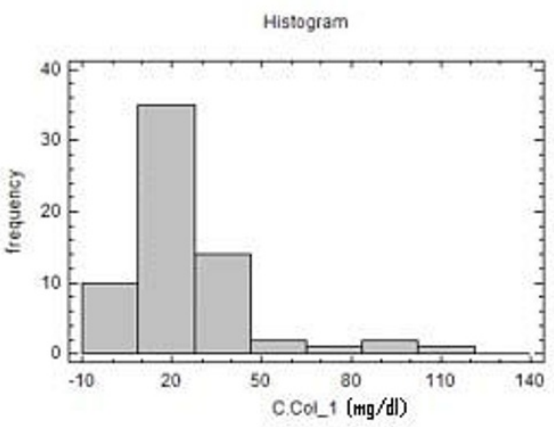

Bar Chart 6:Showing value of Lipaprotein-\$ in patients of OSMF

\section{Figure 7}

Showing Value of Lipoprotein-A in patients of OSMF Bar. 


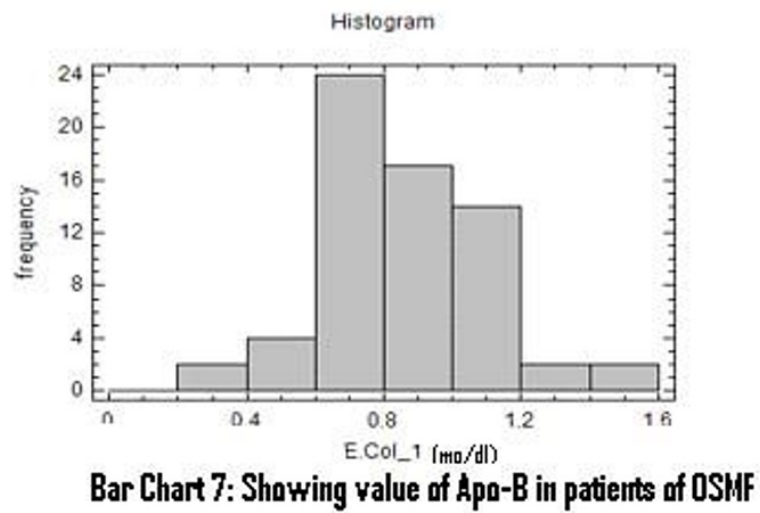

Figure 8

Showing Value of Apo-B in patients of OSMF.

important to carry out important biological functions. Cholesterol is vital for maintenance of integrity of biological membranes and cellular uptake. Regulation of cholesterol is mediated by lipoprotein receptors. Plasma triglycerides and cholesterol are packed into lipoproteins for transport. Cholesterol is an essential constituent of lipoprotein fractions like LDL, HDL and VLDL. Seventy five percent of the plasma cholesterol is transported in the form of LDL. Cells sequester cholesterol from LDL fraction of lipoproteins. Kesaniemi et al reported that LDL receptors are necessary for metabolizing circulating LDL levels and nearly $80 \%$ of the plasma LDL is cleared by LDL receptors [23]. High activity of LDL receptors attributes for lowering the serum cholesterol levels. The individuals having deficient or defective $\mathrm{LDL}$ receptors remove plasma LDL at much lower rate and have considerably elevated levels [24].

HDL and Apo- $A_{1}$ levles may be a useful indicator reflecting initial changes occurring in pre-cancerous and neoplastic conditions. A significant decrease in levels of HDL and Apo-A1 was also observed in this study. This was in accordance with previous reports $[10,25]$ which reported that lower HDL is an additional predictor of oral premalignant condition and it might be a consequence of disease that is mediated by utilization of cholesterol by membrane biogenesis. Schatzkin et al also observed an inverse relationship between serum cholesterol and oral pre-malignant condition [26].

\section{Future strategies}

The evidence suggests that precancerous lesions are able to remodel/metabolize lipids for their growth and to generate phospholipids membrane. Thus, the identification and characterization of more enzymes involved in these pathways will be more important for the proper understanding of these steps. Recent progress in molecular biology will assist researchers in the near future to identify the genes and enzymes of lipid metabolic pathways.

The change in lipid levels may have a diagnostic or prognostic role in the early diagnosis or prognostication of oral premalignant and malignant lesions. The findings strongly warrant an in-depth study of alterations in plasma lipid profile in these patients.

\section{Abbreviations}

HDL: High Density Lipoprotein; LDL: Low density lipoprotein; VLDL: Very Low Density Lipoprotein; SRE: sterol regulatory element; LPa: Lipoprotein A; OSMF: Oral submucous fibrosis.

Table 3: Value of Apo-AI, Apo-B, Cholesterol, HDL, LDL, Lp-A \& S Triglyceride in OSMF Patients (Total N = 65)

\begin{tabular}{llllll}
\hline & $\begin{array}{l}\text { Average } \\
\text { Value } \\
\mathrm{mg} / \mathrm{dl}\end{array}$ & Min-Max & $\begin{array}{l}\text { Coefficient of } \\
\text { Variation }\end{array}$ & $\begin{array}{l}\text { Standard } \\
\text { Deviation }\end{array}$ & $\begin{array}{l}\text { Normal Value } \\
\text { Min-Max }\end{array}$ \\
\hline Cholesterol & 125.68 & $45.95-241.4$ & $29.09 \%$ & 37.42 & $130-250$ \\
\hline HDL Cholesterol & 32.58 & $15.36-70.4$ & $30.83 \%$ & 10.04 & $35-90$ \\
\hline LDL Cholesterol & 90.61 & $22.4-180.92$ & $34.35 \%$ & 31.13 & $0-129$ \\
\hline S-Triglyceride & 130.14 & $15.7-607$ & $52.94 \%$ & 68.90 & $60-165$ \\
\hline Apo-A I & 1.033 & $0.6-1.42$ & $16.36 \%$ & 0.169 & $1.20-1.76$ \\
\hline Apo B & 0.87 & $0.32-1.51$ & $26.05 \%$ & 0.227 & $0.63-1.76$ \\
\hline Lipoprotein A & 26.87 & $0.89-115.8$ & $79.04 \%$ & 21.24 & $<30.0$ \\
\hline
\end{tabular}




\section{Competing interests}

The authors declare that they have no competing interests.

\section{Authors' contributions}

SP and AKC drafted and analysis the manuscript. HPS and RKS carried out the experimental work. RM and SCG conceived of the study, participated in its design and coordination as well as helped to draft the manuscript. MS and Mamta Singh participated in coordination of the study and helped to draft the manuscript. All authors read and approved the final manuscript.

\section{References}

I. Shafer WG, Hine MG, Levy BM: A text book of oral pathology. Fourth edition. W.B Saunders, Philadelphia; 1993:109-II0.

2. Shah B, Lewis MA, Bedi R: Oral submucous fibrosis I I year-old Bangladeshi girl living in United Kingdom. Br Dent J 200I, 191:130-2.

3. Mehrotra R, Pandya S, Chaudhary AK, Kumar M, Singh M: Prevalence of oral pre-malignant and malignant lesions at a tertiary level hospital in Allahabad, India. Asian Pac J Cancer Prev 2008, 9(2):263-5.

4. Tilakaratne WM, Klinikowski MF, Saku T, Peters TJ, Warnakulasuriya S: Oral submucous fibrosis: review on aetiology and pathogenesis. Oral Oncol 2006, 42(6):56I-8.

5. Pandya S, Chaudhary AK, Singh M, Singh M, Mehrotra R: Correlation of histopathological diagnosis with habits and clinical findings in oral submucous fibrosis. Head Neck Oncol 2009, I(I): 10 .

6. Chang YC, Hu CC, Tseng TH, Tai KW, Li CK, Chou MY: Synergetic effect of nicotine on arecoline induced cytotoxicity in human buccal mucosa fibroblasts. I Oral Pathol Med 200I, 30:458-464.

7. Manoharan S, Kolanjiappan K, Suresh K, Panjamurthy K: Lipid peroxidation and antioxidants status in patients with oral squamous cell carcinoma. Indian I Med Res 2005, I 22:529-534.

8. Forones NM, Falcan JB, Mattos D, Barone B: Cholesterolemia in colorectal cancer. Hepatogastroenterology 1998, 45:|53|-4.

9. Chyou PH, Nomura AM, Stemmermann GN, Kato I: Prospective study of serum cholesterol and site-specific cancers. J Clin Epidemiol 1992, 45:287-92.

10. Patel PS, Shah MH, Jha FP, Raval GN, Rawal RM, Patel MM, Patel JB, Patel DD: Alterations in plasma lipid profile patterns in head and neck cancer and oral precancerous conditions. Indian J Cancer 2004, 4I:25-3I.

II. Hazarey VK, Erlewad DM, Mundhe KA, Ughade SN: Oral submucous fibrosis: study of $\mathbf{1 0 0 0}$ cases from central India. J Oral Pathol Med 2007, 36(I): I2-7.

12. Kritchevsky SB, Wilcosky TC, Morris DL, Truong KN, Tyroler HA Changes in plasma lipid and lipoprotein cholesterol and weight prior to the diagnosis of cancer. Cancer Research 1991, 51:3198-3203.

13. Fredrickson DS, Levy RI: Familial hyperlipoproteinemia. In the metabolic basis of inherited disease 3rd edition. Edited by: Stanbury JB, Wyngaarden JB, Fredrickson DS. New York, McGraw-Hill Book co; 1972.

14. Tietz NW: Fundamentals of Clinical Chemistry. W.B. Saunders Company Philadelphia, USA; 1994.

15. Kaul D: Do human platelets possess LDL-receptor specific for apoprotein 'B' or cholesterol? Curr S 1993, 65:883-86.

16. Kaul D: Receptor-Ck and leukemogenesis. Leuk Res 1998, 22:389-94.

17. Kaul D, Kaur M: Receptor-Ck regulates the expression of cyclin-dependent kinase inhibitors. Mol Cell Biochem 1999, 200: $183-86$.

18. Kaur M, Kaul D, Sobti RC: Receptor-Ck dependent regulation of genes involved in the cell cycle. Mol Cell Biochem 1998, | 8 |: | 37-42

19. Kaul D, Khosla VK: Molecular basis of 'cholesterol feedback lesion' in CNS tumors. Nerol India 2000, 48: I74-77.

20. Maxfield FR: Plasma membrane microdomains. Curr Opin Cell Biol 2002, 14:483-87.
21. Simons K, Toomre D: Lipid rafts and signal transduction. Nat Rev Mol Cell Biol 2000, I:3 I-9.

22. Allampallam K, Dutt D, Nair C, Shetty V, Mundle S, Lisak L: The clinical and biologic significance of abnormal lipid profiles in patients with myelodysplastic syndromes. J Hematother Stem. Cell Res 2000, 9:247-55.

23. Kesaniemi YA, Witzlum JL, Heinbrecher UP: Receptor-mediated catabolism of low density lipoprotein in man. Quantitation using glycosylated lipoprotein. J Clin Invest 1983, 7 I:950-9.

24. Brown MS, Kovanen PT, Goldstein JL: Regulation of plasma cholesterol by lipoprotein receptors. Science I98I, 2 I 2:628-35.

25. Dessi S, Batetta B, Pulisci D, Spano O, Cherchi R, Lanfranco L: Altered pattern of lipid metabolism in patients with lung cancer. Oncology 1992, 49:436-4I.

26. Schatzkin A, Hoover RN, Taylor PR, Ziegler RG, Carter CL, Albanes $D$ : Site-specific analysis of total serum cholesterol and incident cancers in the National Health and Nutrition Examination Survey I epidemiologic follow-up study. Cancer Res 1988 , 48:452-8.
Publish with Biomed Central and every scientist can read your work free of charge

"BioMed Central will be the most significant development for disseminating the results of biomedical research in our lifetime. "

Sir Paul Nurse, Cancer Research UK

Your research papers will be:

- available free of charge to the entire biomedical community

- peer reviewed and published immediately upon acceptance

- cited in PubMed and archived on PubMed Central

- yours - you keep the copyright 